four), though in one of the cases the leg had to be amputated. In seven other cases death followed the ligature of the artery above, which in six was the external iliac and in one the femoral. In the eighth fatal case, after the failure of digital pressure, galvano-puncture was used twice. On the second occasion it caused inflammation and threatened rupture of the sac. The femoral artery was tied, but the patient (a very old man, aged seventy-five) sank from exhaustion.

It is a singular circumstance, that besides the case referred to above, in which, after the failure of pressure, the sac was laid open and the artery tied above and below, there are eight other cases in which the old operation was performed in the thigh. In most of these cases the operation was performed, as in those published by Mr. Birkett* and Mr. Henry Smith, on account of the subcutaneous rupture, or so-called "diffusion" of the aneurism. In one case, however, it was necessitated by a wound of the aneurism, which had been opened by mistake for an abscess. In this case the vessel could not be found, and the limb was amputated with success. In another case, which was under Mr. Syme's care in 1862, and which seems to have been one of iliofemoral aneurism, the sac was laid open upwards and downwards to the parts where the artery assumed the normal calibre, and was tied at either end of the sac, in doing which Poupart's ligament was cut through. The patient died on the eighteenth day after the operation. The cause of death is not stated.

Besides this case, only two of the other patients died. One was under Mr. Holmes Coote's care at St. Bartholomew's Hospital in 1867, and the case will be found in the Reports of that Hospital. As Mr. Coote remarks, it was rather one of wounded artery than of aneurism. The vein was also wounded, but was apparently not tied. Severe bleeding came on in the night, and then the thigh was amputated, but the patient sank. The other was a case of rupture of the profunda artery from a sprain, in which very great difficulty was experienced in finding the injured vessel, and the patient died from the shock of the protracted operation. I ought, perhaps, to mention that in one of the successful cases, the femoral vein was accidentally included with the artery in the ligature.

To these cases I might add another which Mr. Gay published some years ago.t I had the opportunity of seeing the patient last year, and he was then sinking from visceral disease, quite unconnected, however, with the operation, which has been in all respects successful, the wound having soundly healed, the circulation of the limb completely re-established, and the man as active as his weakly general condition permitted; in fact, thoroughly cured of his formidable disease. He has since died, but no postmortem examination was permitted.

This record of a very formidable list of cases, treated decisively and radically by an operation so grave as the old operation on femoral aneurism must be allowed to be, certainly shows that its success in the hands of the hospital surgeons of the present day is greater than we should have à priori been inclined to expect; and I have no doubt that the treatment pursued in these cases is that which surgeons should adopt in all cases of ruptured femoral aneurism, though I am aware that such a complication has not prevented the successful performance of the Hunterian operation. In The LANCET, vol. ii. 1851, p. 30, is an example under the care of Mr. Hovell, of Clapton, in which he tied the femoral artery on Hunter's principle with complete success, in a woman affected with aneurism in the lower part of the thigh, which had burst through the skin, causing hæmorrhage to the extent of a pint. Suppuration took place in the sac, but no further bleeding, and the tumour disa ppeared.

* Med. Chir. Trans., 1., 431.

+ The Lancer, vol, i. 1868, p. 780

Bequests \&c. to Medical Chamities-The Salisbury Infirmary has, as appears from the annual report, become entitled to a legacy of $\$ 3000$ under the will of Mr. Henry Cooper, of Salisbury, and a contingent one of $\$ 2000$ under the will of Mrs. Maria S. Huxtable, of Sutton-Wal. dron; and received a further $£ 100$ from the Dowager Marchioness of Westminster, $\$ 100$ from Mr. and Mrs. Staples, of Belmont; and seven separate legacies of $\$ 100$ each, and one of $\& 5$.

\section{ON IPECACUANHA SPRAY IN WINTER COUGH AND BRONCHITIC ASTHMA.}

\author{
BY SYDNEY RINGER, M.D.; AND \\ WILLIAM MURRELL.
}

THE successful use of a secret remedy by a well-known practitioner induced us to try the effect of inhalation of ipecacuanha spray. Our results have been so satisfactory that we desire to draw the attention of the profession to this mode of treating these obstinate complaints-winter cough and bronchial asthma. Our observations were made during January and February. Whilst under this treatment the patients took only coloured water, and continued their usual mode of livg in all respects.

We shall first ref $r$ to winter cough. We have made observations on twenty-fire patients, whose ages varied between forty-five and seventy-two, with one exceptionthat of a woman of thirty-two years. We purposely chose severe cases. In order to avoid burdening this paper with too much detail, we give here a typical case, which will serve in most points to illustrate the condition of the patients. Subsequently we shall report two actual cases in full.

The patient has been troubled with winter cough perhaps for many years. During the summer he is pretty well; but during the cold months, from October to May, he suffers sometimes without intermission, occasionally getting a little better and then catching cold; or perhaps be may lose his cough for a few weeks, but again takes cold on the slightest exposure. So short is the breathing that he can walk only a few yards, especially in the cold air, and finds it hard work to get upstairs, and is often quite unfitted for active life. The breathing grows worse at night, so that he cannot sleep unless the head is propped up with several pillows. He is troubled, too, with paroxysmal dyspnce, usually at night, which may last several hours, and compels him to sit up. Sometimes the breathing is difficult only on exertion; and in those cases it is made much worse by fogs, east winds, or damp. The expectoration varies greatly; in a few cases there is very little; usually, however, it is rather abundant, and consists of mucus or pus, often with little or no rhonchus in the chest. It is often difficult to expel the expectoration. The cough is generally very violent, frequent, hacking, and paroxysmal, and the fits may last ten or twenty minutes, and even excite vomiting. They are generally brought on by exertion; nay, in bad cases so easily are they provoked that the patient is afraid to move, or even to speak. The cough and expectoration are much worse in the morning on waking: Sometimes the cough is slight, and then the expectoration is generally scanty, the distressed breathing being the chief symptom. The patient generally wheezes badly, especially at night, and in a bad case the legs are swollen. The patient is emphysematous; there is often no rhonchus, or only sonorous and sibilant or a little bubbling rhonchus at both bases.

In this common but obstinate complaint our results have been very striking, although in many of our patients so bad was the breathing that, on being shown into the outpatients' room, they dropped into a chair, and for a minute or so were unable to speak, or only in monosyllables, having no breath for a long sentence. We used the ordinary sprayproducer, with ipecacuanha wine pure or variously diluted. On the first application it sometimes excites a paroxysm of coughing, which generally soon subsides, but if it continues a weaker solution should be used. The patient soon becomes accustomed to it, and inhales the spray freely into the lungs. At first a patient inhales less adroitly than be learns to do afterwards, as he is apt to arch his tongue so that it touches the soft palate, and consequently less enters the chest than when the tongue is depressed. The spray may produce dryness or roughness of the throat, with a raw sore sensation beneath the sternum, and sometimes it causes hoarseness; whilst, on the contrary, some hoarse patients recover voice with the first inhalation. As they go on with the inhalation, they feel it getting lower and lower into the chest till many say they can feel it as low as the ensiform cartilage. The dyspnoea is the first symptom relieved. The night after the first application the paroxysmal dyspnoea mas 
often improved, and the patient had a good night's rest, although for months before the sleep was much broken by shortness of breath and coughing. The diffeulty of breathing on exertion is also quickly relieved; for of ten after the first administration the patient walked home much easier than he came to the hospital, and this improvement is continuous, so that in one or two days or a week the patient can walk with very little distress, a marked improvement taking place immediately after each inhalation; and although after some hours the breathing may again grow a little worse, yet some permanent improvement is gained, unless the patient catches a fresh cold. We nave heard patients say that in a week's time they could walk two miles with less distress of breathing than they could walk a hundred yards before the spray was employed. In some instances two or three days' daily spraying is required before any noticeable im provement takes place, this comparatively slow effect being sometimes due to awkward inhalation, so that but little ipecacuanha passes into the bronchial tubes. The effect on the cough and expectoration is also very marked, these both greatly decreasing in a few days, though the improvement in these respects is rather slower than in the case of the breathing. Sometimes for the first few days the expectoration is rather increased. It speedily alters in character, so that it is expelled much more readily, and thus the cough becomes easier, even before the expectoration diminishes.

Treated in this way the patient is soon enabled to lie down at night with his head lower, and in a week or ten days, and sometimes earlier, can do with only one pillow. This improvement occurs in spite of fogs, damp, or east winds-nay, even whilst the weather gets daily worse, and when the patient is exposed to it the chief part of the day. All these patients came daily to the hospital. Of course it is much better to keep the patient in a warm room.

Here are short notes of two cases, the first a very successful one.

J. H_- aged seventy-two, has had a winter cough for the last three years. The cough comes on in fits, and is very bad at night. Fogs greatly aggravate it. She spits about a teacupful of thick yellow phlegm in the twentyfour hours. So bad is her breath that she cannot lie down at night, but is propped up with pillows, and is always wheezing. She is obliged to stay at home for weeks together. Her lungs are emphysematous, with only sonorous râles. After the first inhalation there was great improvementfreedom from cough all night, with much easier breathing. Further imirovement took place after the next day's inhalation, and still more after the third, so that on the sixth day of treatinent, and after three inhalations, she reported that her breathing "was not near so troublesome; thinks nothing of it now; does not spit up balf as much," and the expectoration is white and frothy. This poor woman was loul in ber praise of the treatment; said she "never expected it," and "when first she came to the hospital thought she should never get about again." J. H- is now suffciently recovered to take charge of a shop, though before her attendunce at hospital she had not been out of her room for four months. She was discharged, and called a month afterwards to say there had been no relapse.

Now comes a less tractable instance, a fair specimen of one of the more obstinate cases.

M. A-, aged thirty-two, came to the hospital January 29 th with a winter-cough of many years' standing, and worse this winter than ever before. The cough is paroxysmal, the slightest exertion, even talking, bringing on an attack. The paroxysms vary much, but generally last ten minutes. In the twenty-four hours she spits about a teacupful of thick yellow phlegm. Extremely short-breathed, and she is quite unable to do her house work, and at night is unable to sleep unless propped up with three pillows and a bolster. The breathing always gets worse at night. Fogs increase all her troubles. Has been hoarse for weeks, and if she talks much she altogether loses her voice. Her chest is very sore with coughing. She is emphysematous, and her breath-sounds are obscured by cooing râles.

Feb. 3rd.-The patient, who has had an inhalation on five successive days, now says she is in every way much better. The breathing is much easier; the cough is not nearly so violent; her chest is less sore; the expectoration is much less; and there is very little hoarseness.

6th, - The inhalations have been continued daily. The patient says she is better than she has been all the winter. The improvement in her breathing is very great, and she can now do with only one pillow at night instead of three. She sleeps much better. The cough is greatly improved, and, instead of being "aggravated" towards night, is now better at that time. Expectoration has almost ceased.

10th.- Has had only one inhalation since last date, and her breathing has been a little more distressed.

12th.- Has had an inhalation daily, and the dyspnoea has again nearly disappeared.

17th.-Has had but one inhalation since last date. The cough now has almost left her, and she often goes twelve hours without a fit. Her breathing is so much better that she now does her own house-work, and is not propped up at night.

Discharged after ten inhalations and nineteen days' treatment.

A month afterwards she came to the hospital to say that her breathing was all right, and that she had been perfectly well since her discharge, with the exception of a slight hacking cough.

All but one of the twenty-five patients were benefited. In one case the improvement was very gradual, but there was evident temporary improvement after each inhalation. In twenty-one cases the average number of inhalations required was $9 \cdot 4$, and the average number of days was twelve, before the patients were discharged cured. 'The greatest number of inhalations in one case was eighteen, and the smallest three. The case longest under treatment required twentyfour days; the shortest, four.

In employing the ipecacuanha spray, in order to ensure as far as possible only its topical effects, we were careful to direct the patient to spit out and even to rinse out the mouth at each pause in the administration, for a much larger quantity of the wine collects in the mouth than passes into the lungs. If this precaution is not adopted, sometimes enough is $\mathrm{swallowed}$ to excite nausea and even vomiting, by which means the bronchial mucus is mechanically displaced, and of course in this way effects temporary improvement. Even when this precaution was observed, a protracted inhalation will excite nausea and sometimes vomiting by the absorption of the wine by the bronchial mucous membrane; though, strange to say, when thus induced, vomiting was long delayed, even for several hours-nay, sometimes not till the evening, though the inhalation was used in the morning. In the reported cases, however, improvement was not due to the nauseating effects of the spray, for we took care to avoid this contingency by administering a quantity inadequate to produce this result. The duration of each inhalation will depend on the amount of spray produced by each compression of the elastic ball, and on the susceptibility of the patient to the action of ipecacuanha. As a rule, the patient at first will bear from twenty squeezes of the spray without nausea, and will soon bear much more. After two or three squeezes, especially on the commencement of the treatment, we must pause a while. It is necessary to look at the patient's tongue and tell him to learn to depress it, for if the tongue is much arched it will hinder the passage of the spray to the lungs. It is a good plan to tell the patient to close his nose with his fingers and to breathe deeply. The inhalation should be used at first daily, and in bad cases twice or thrice in the day; afterwards every other day suffices, and the interval may be gradually extended. If the ipecacuanha wine is diluted, then the spray must be used a longer time. In cold weather the wine should be warmed.

We have tried the spray with very satisfactory results in a few cases of the following more severe though closely allied disease:-A patient for several years has suffered from severe winter congh, with much dyspnoea, cough, and expectoration; and on several occusions bas spat up a considerable quantity of blood. The physical signs denote slight fibroid consolidation, with excavation of both apices, and much emphysema, perhaps atrophous in kind. There is little or no rhonchus, and no fever. The expectoration may be slight or very abundant, muco-purulent or purulent. The dyspncea is, perhaps, very severe; and is so paroxysmal as to justify calling the case bronchial asthma, with emphysema, and fibroid phthisis. In these cases the ipecacuanha spray is almost as beneficial as in the preceding. It soon controls the dyspnoea, thus enabling the patient to sleep, and greatly lessens expectoration and cough; and by these 
means really improves the general health. As in the previous cases, the first inhalation may considerably improve the breathing, though the effects are not so permanent, the dyspnoea returning in the evening; so that spraying is needed night and morning, and may be necessary for weeks or months, the ipecacuanha appearing rather to give relief than to permanently cure the dyspncea.

We have used the spray in two cases of true and severe bronchial asthma, with very opposite results. In one severe case, accompanied by a great deal of bronchitis, it gave very great relief. The other patient, not so ill, has been all his life asthmatical; and on catching even a slight cold his breathing becomes greatly oppressed. In this instance each application of the spray considerably aggravated the dyspnoea, even when the wine was diluted with an equal quantity of water. Possibly a still weaker solution might have been borne; but we are inclined to think that in this case any quantity of ipecacuanha would have disagreed, as the tightness of breathing increased almost immediately the inhalation was begun.

The successful case was a very severe one. For years this woman had suffered from bronchitic asthma, and when she applied to the hospital was unable to lie down owing to shortness of breath. She suffered also from violent paroxysmal dyspnœa, the worst attack beginning about three A.M., compelling her to start out of bed and struggle for breath. She was very emphysematous; her voice was very hoarse. The first inhalation removed the hoarseness, and much improved her breathing, which continued freer till midnight, when the dyspnoea returned. The cough was eased, and she expectorated more freely. Each inhalation always gave her very great and marked relief. She walked to the hospital with great difficulty, and was constrained to stop frequently. On entering the room she could not speak, but laboured violently and with loud wheezing to get her breath. A few inhalations would gradually set the breathing free, so that the air entered more and more, and the wheezing gradually left, till, on the completion of the inhalation, she could breathe without diffculty. As the breathing improved she could feel the spray descending lower and lower in her chest. At first it would seem to reach only the back of the tongue, then the top of the sternum, then descend to midsternum, and at last she felt as if it reached as low as the pit of the stomach. This improvement was maintained through the day, but at evening a relapse would occur, so that her nights, though at first bad, were still better than before the treatment. Soon, however, the effects became more lasting, and she slept well. On discontinuing the spray, however, her breathing again grew worse, and she was obliged to revert to the treatment; but unfortunately she so soon caught cold, and so bad was the weather, that she was obliged to stay away for days together. Whilst her breathing improved the cough and expectoration also improved, but these two symptoms continued rather troublesome. Probably in bad bronchitic asthma the spray must at first be used tivice a day or of tener, and must be continued for some time to ward off the dyspncea, for in these obstinate chronic cases the bronchitis may take a considerable time to cure. So marked was the improvement from the spray that the patient and her friends expressed their astonishment, especially at the prompt relief it gave.

\section{ON DIABETES FROM CARBONIC OXIDE.}

\section{By B. W. RICHARDSON, M.D., F.R.S.}

TrE brief notice of Dr. Pavy's interesting experiments on the production of diabetes by the inhalation of the fumes of the Lycoperdon giganteum (common puff-ball), reported in The LANCET of last week, calls from me the following brief notice.

Immediately after I had discovered the anæsthetic action of the fumes of burning lycoperdon-viz., in 1853,-research was made as to the agent in the fumes that produced the physi.logical effect. I commenced this inquiry on my own account; but before my analysis was completed $I$ received a request from Snow to visit him at his laboratory in Sackville-street to witness his analysis. I went as desired, and was shown, beyond all dispute, by Snow, that the active agent in puff-ball smoke is carbonic oxide gas. A short time afterwards, and before Snow had time to publish his new observation, Thornton Herapath sent me word that he had made the same discovery. Herapath published an account of his research at once, so that the originality of the observation that carbonic oxide is a product of the slow combustion of the lycoperdon has very justly rested with him.

When the matter under inquiry had been demonstrated thus far, I commenced a series of researches on the comparative action of carbonic oxide upon animals. I found precisely the same effects from this gas when it was administered, well diluted with air, as were observed from the fumes of the lycoperdon. The insensibility produced was the same, and the peculiar bright redness of the arterial blood was the same.

At the same time a most interesting new point was ob. served-namely, that dogs made to inhale carbonic oxide were rendered temporarily diabetic. I collected the urine passed after exposure to the gas, and found it contained glucose in considerable quantity. I made this subject a point of illustration in a lecture on diabetes delivered at the Grosvenor-place School of Medicine on November 22nd, 1861 ; and the report of the lecture, published by Mr. Macpherson in the Medical Times and Gazette of March 8th, 1862 , although it is merely an abstract of the lecture, contains a brief but correct notice of the fact named. In an after experiment I found that coal-gas, which contains carbonic oxide, produces the same conditions as diluted carbonic oxide-naniely, redness of the venous blood and saccharine urine.

A corroborative and singularly interesting observation has been made later still by Dr. Hesse. He noticed that two men who had been exposed, by accident, to the fumes arising from a stove heated by pit-coal, when they had recovered from the more imminent symptoms, were suffering from diabetes; their urine was charged with diabetic sugar

In my experiments on the inhalation of oxygen, which have been extensive, $I$ have compared the action of oxygen with that of carbonic oxide. In respect to the urine, it has seemed to me that there is a difference, and that sugar can only be produced freely by the action of carbonic oxide. A prolonged inhalation of an atmosphere in which carbonic acid was present in such weak dilution with common air as to cause torpor without asphyxia caused, however, evidence of sugar.

The hypothesis I formed, when I first observed the action of carbonic oxide in producing saccharine urine, was that the gas exerted its toxic influence through the nervous system. I doubt now whether this view is correct. In the last few years the researches that have been published on carbonic oxide, especially by Dr. Arthur Gamgee in his splendid paper published in the Journal of Anatomy and Physiology for May, 1867, point, I think, to the possible conclusion that the effect of the gas may be chemical and direct in the production of glucose in the animal secretion.

In Dr. Pavy's experiments with the fumes of the Lycoperdon giganteum, the agent at work has certainly not been oxygen, but carbonic oxide; and as my experiments have proved that the inhalation of carbonic oxide will produce artificial diabetes, and as it has been proved from the experiments of Bernard, Meyer, Hoppe, and Gamgee that carbonic oxide has the power of displacing the oxygen of the blood, I infer that when sugar is formed by the synthetical method now being considered, carbonic oxide, and not oxygen, is, either directly or indirectly, the cause of the phenomenon.

Hinde-street, $W$.

\section{A CASE OF FISTULOUS PNEUMOTHORAX.}

\section{By THOMAS COLE, M.D.Lond., M.R.C.P.,} PHYSICIAN TO THE BOYAL UNITED HOSPITAL, BATH.

JANE W-, aged eighteen, a pupil-teacher, consulted me on February 10th, 1874. She had been weak and ailing for some time, and was very anæmic. There was no cough; no special disease was found. Rest and tonic treatment seemed in a few weeks to have restored her to health; so much so that she returned to her duties, though without my permission. Her mother came to me about ten days 